\title{
Recurrent gastrointestinal bleeding in a man with Osler-Weber-Rendu syndrome and intestinal varices
}

\author{
ROBERT N. CLARK, MD, FRCPC, WILLIAM G. PATERSON, MD, FRCPC, \\ LAURINGTON R. DA COSTA. MD, FRCP (LOND), FACP, FRCPC, IVAN T. BECK, MD, PHD, FRCPC, FACP
}

ABSTRACT: A patient with Osler-Weber-Rendu disease and idiopathic intestinal varices who presented with recurrent gastrointestinal hemorrhage and iron deficiency anemia is reported. The unique coexistence of these two rare disorders is discussed and the literature reviewed. Can J Gastroenterol 1988;2(2):65-66

Key Words: Bleeding, Gastrointestinal, Intestinal varices, Telangiectasias

H EREDITARY HEMORRHAGIC TELANgiectasia is a rare but well documented cause of recurrent intestinal bleeding Even more rare is the development of colonic varices in the absence of portal hypertension. This paper reports a unique case of recurrent lower gastrointestinal hemorrhage where both of these conditions were present.

\section{CASE PRESENTATION}

A 44-year-old male inmate of a Federal penitentiary was recently investigated in this unit for recurrent episodes of gastrointestinal bleeding.

The patient was first recognized as having Osler-Weber-Rendu disease in 1977 when the typical telangiectasias were first noted on his lips. For the previous seven years he had experienced repeated bouts of red blood per rectum, attributed up until that time to hemorrhoids. A hemorrhoidectomy did not influence the almost monthly episodes of bleeding.

At the time of his initial assessment,

and on many occasions subsequently, he had developed profound iron deficiency anemia, often to the range of 60 to 70 $\mathrm{g} / \mathrm{L}$, and not compensated for by chronic oral iron therapy. He had developed unstable angina on several occasions during periods of worsening anemia and, in 1986, underwent coronary artery bypass graft surgery for occlusive coronary artery disease.

At no time over the past 10 years had the patient been seen and assessed while actively bleeding, but stools had been positive for occult blood on several occasions. The remainder of the history, physical examination and laboratory investigations were normal. In particular, there was no clinical or biochemical evidence of underlying liver disease or portal hypertension. There was no suggestion of coagulopathy at any time. There had been no previous abdominal surgery.

The patient had been extensively investigated on several occasions, particu-

Gastrointestinal Diseases Research Unit and the Department of Medicine, Queen's University, Kingston, Ontario

Correspondence and reprints: Dr William G. Paterson, Division of Gastroenterology,

Department of Medicine, Hotel Dieu Hospital, 166 Brock Street, Kingston, Ontario K7L 5G2. Telephone (613) 549-5615

Received for publication December 7, 1987. Accepted February 12, 1988 larly over the past year, during which time he had been transfused with over 20 units of packed red blood cells. Esophagogastroduodenoscopy, small bowel enema and air contrast barium enema had failed to demonstrate any abnormality. In particular no varices were visualized in the esophagus, stomach or duodenum during upper endoscopy. At colonoscopy large colonic varices (Figure 1) were observed diffusely throughout the left and right colon and also in the terminal ileum (Figure 2). In addition, there were 1 to $2 \mathrm{~mm}$ diameter telangiectatic vascular lesions scattered in the region of the splenic flexure and descending colon (Figure 3). Several of these lesions were coagulated with a bicap electrode, (ACMI, BC-60B BICAP), despite uncertainty that these were the cause of the gastrointestinal hemorrhage.

During the same admission a superior mesenteric artery angiogram, with delayed venous phase, failed to identify any abnormality. Ultrasound of the abdomen showed the portal vein to be patent and the spleen to be of normal size. The liver parenchyma was unremarkable, however, a 3 to $4 \mathrm{~cm}$ diameter hyperchoic lesion was detected in the right lobe. A technetium 99 sulphur colloid liver-spleen scan also demonstrated a $3 \mathrm{~cm}$ filling defect in the right lobe of the liver. Otherwise, the hepatic uptake of technetium 99 was homogeneous and there was no bone marrow uptake or splenomegaly to suggest por tal hypertension. Subsequently a pooled techne- 


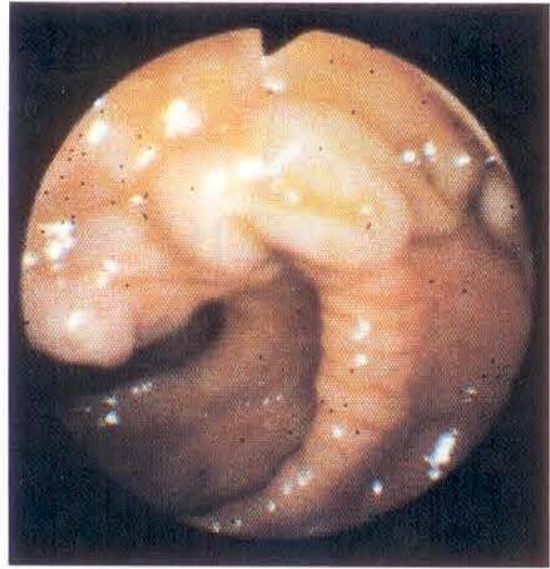

Figure 1) Endoscopic view of varices in the ascending colon

tium red blood cell scan was performed which revealed a 'delayed hot spot' in the right lobe suggesting that the liver lesion was a hemangioma.

\section{DISCUSSION}

The association between Osler-WeberRendu hereditary telangiectasia and colonic varices has never been reported.

Colonic varices are relatively rare being found in only $0.07 \%$ of 2912 consecutive autopsies reported by Feldman et al (1). In the majority of cases, colonic varices are attributable to portal hypertension (2), usually in the setting of alcoholic liver disease. Less common causes of colonic varices include large bowel venous anomalies (3) and selective mesenteric vein obstruction (4). Rarely, chronic heart failure or constrictive pericarditis may be responsible for impaired colonic venous return and result in colonic varices (2). The management of recurrent colonic variceal bleeding from portal hypertension is either resection of the affected portion of bowel, or portosystemic decompressive shunt (5).

Varices are even less likely to be found

\section{REFERENCES}

1. Feldman M, Smith VM, Warner CG.

Varices of the colon. JAMA

$1962 ; 179: 729-30$

2. Izsak EM, Finlay JM. Colonic varices - 3 case reports and a review of the literature. Am J Gastroenterol 1980;73:131-6.

3. Lieberman DA. Krippaehne WW, Melnyk CS. Colonic varices due to intestinal cavernous hemangiomas. Dig Dis Sci 1983;28:852-8.

4. Soper N], Rikkers LF, Miller FJ. Gastro-

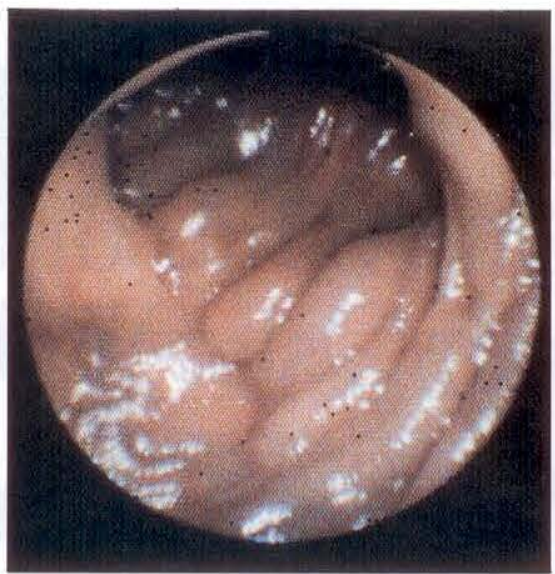

Figure 2) Endoscopic view of varices in the terminal ileum

in the small bowel, as was demonstrated in the present patient. Falchuk and colleagues (6) reported gastrointestinal bleeding from ileal varices, which were believed to arise as a result of localized mesenteric hypertension due to adhesions. Except for such unusual circumstances, the small bowel is generally spared extensive por tosystemic collaterals, which are common in the cardiacazygous system, abdominal wall and rectum (7). Although this was not the case in the present patient, small bowel varices can be demonstrated by enteroclysis (8). Active bleeding from intestinal varices can be diagnosed by scintigraphy, using labelled red blood cells, if the examination is performed during an episode of active hemorrhage (9).

The only report which links colonic varices and benign vascular disease of the bowel is that of Lieberman and others (3). These authors describe a patient with severe lower gastrointestinal bleeding, rectosigmoid varices and caver nous hemangiomas involving the skin, lower extremities and distal colon. The authors suggest that the underlying cavernous

intestinal hemorrhage associated with chronic mesenteric venous occlusion. Gastroenterology 1985;88:1964-7.

5. Pickens CA. Tedesco FJ. Colonic varices - unusual cause of rectal bleeding. Am J Gastroenterol 1980;73:73-4.

6. Falchuk KR, Aiello MR, Trey C, Costello P. Recurrent gastrointestinal bleeding from ileal varices associated with intra-abdominal adhesions: Case report and review of the literature. Am J Gastroenterol 1982;77:859-60.

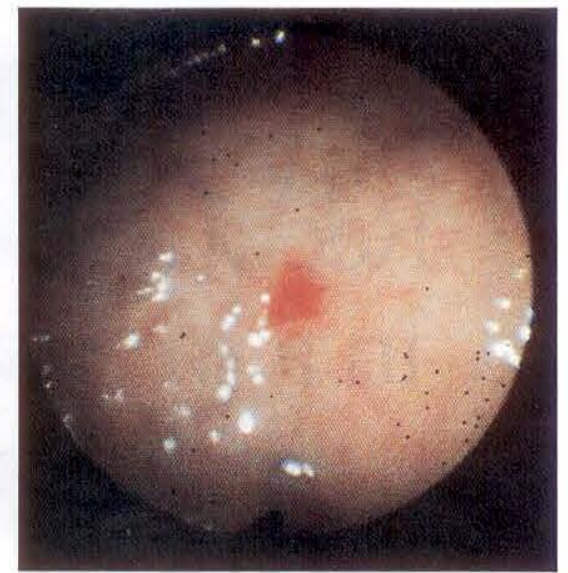

Figure 3) Endoscopic view of telangiectactic lesion of the proximal descending colon

hemangioma with associated venous proliferation produced the colonoscopically visualized varices in the rectosigmoid. The present patient presented with two rare intestinal conditions, and the probability of these co-existing due to chance alone is quite small. Thus it is tempting to speculate that the two are interrelated. It is possible that arteriovenous shunting associated with intestinal telangiectasias results in increased flow and secondary dilatation of intestinal veins, however, the relatively small number of colonic telangiectasias seen in the patient would argue against this hypothesis. Nevertheless, it is possible that more extensive telangiectactic lesions were present deep to the mucosa and out of view of the endoscope.

Given the uncertainties regarding the exact site and source of bleeding, the authors intend to manage this patient with blood transfusion as necessary, and undertake colonic or small bowel resection only for an exsanguinating bleed or, if they are able to localize a focal bleeding source, by angiography or red blood cell bleeding scan.

\section{Silk DBA, Williams R. Portal}

hypertension. In: Wright R, ed. Liver and Biliary Disease. Pathophysiology,

Diagnosis, Management. Toronto: WB

Saunders Co, 1979

8. Agaral D, Scholz FJ. Small bowel varices demonstrated by enteroclysis. Radiology 1981; 140:350.

9. Royal HD, Papanicolaou N, Bettmann M $\mathrm{McNeil}$ BJ. Scintigraphic identification of bleeding duodenal varices. Am J Gastroenterol 1980;74:173-5. 


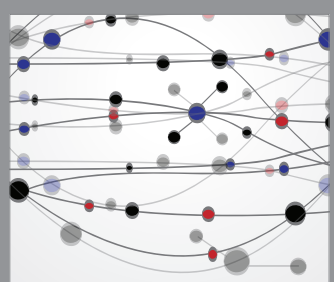

The Scientific World Journal
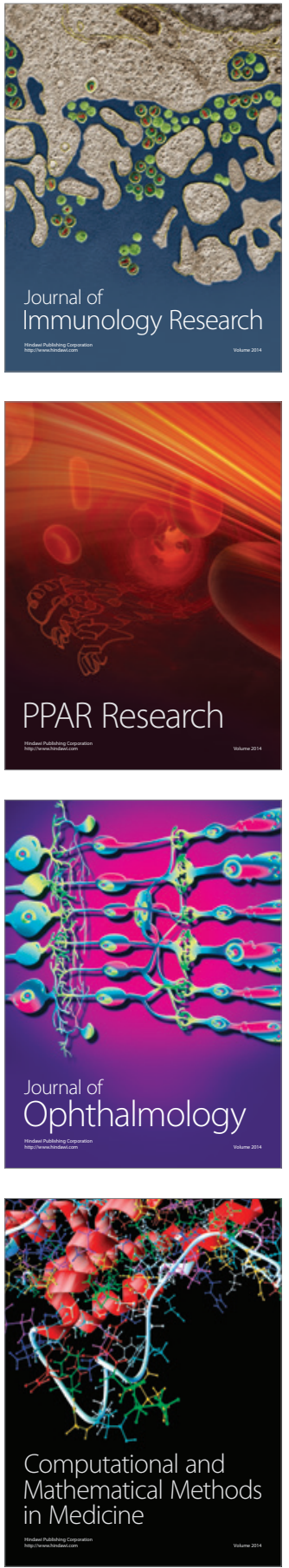

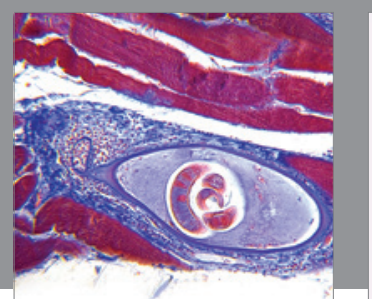

Gastroenterology Research and Practice

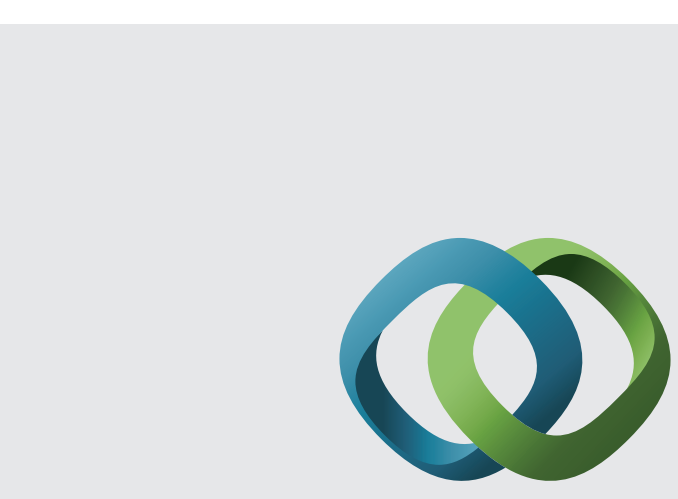

\section{Hindawi}

Submit your manuscripts at

http://www.hindawi.com
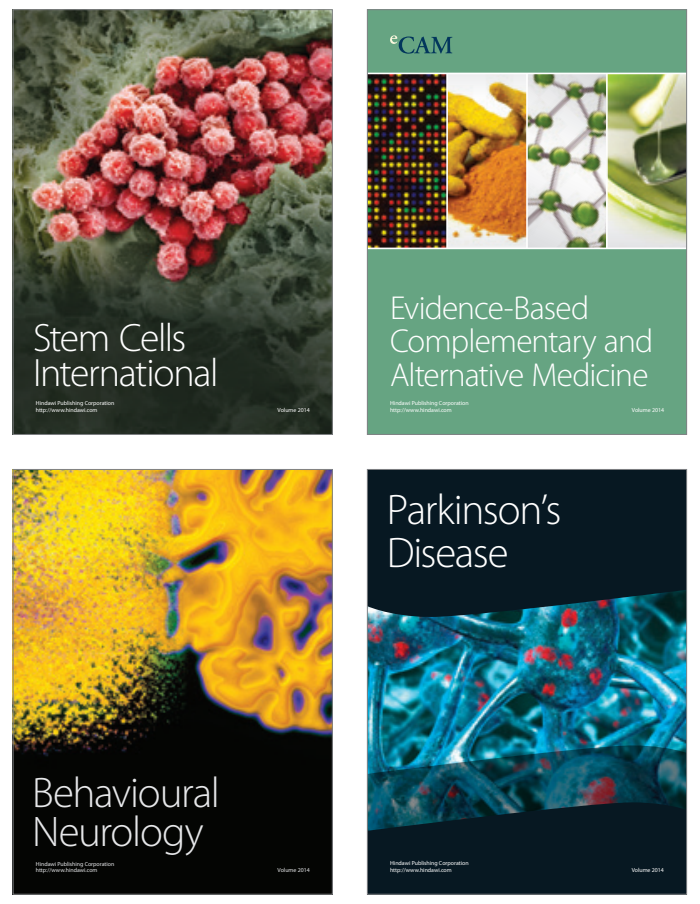
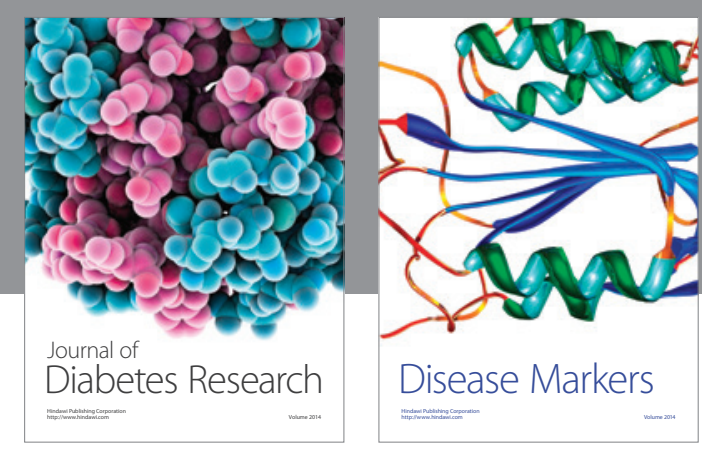

Disease Markers
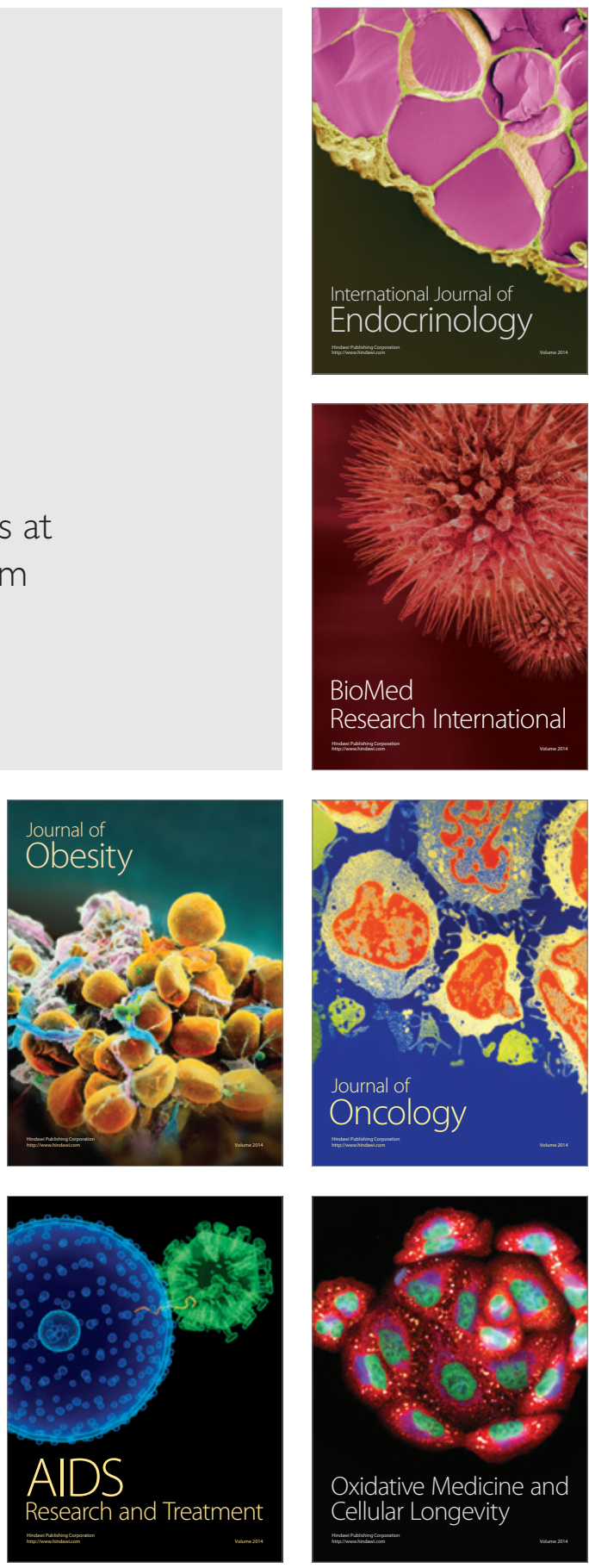